\title{
Software architecture for highly automated driving: Easier and faster system development
}

Marcus Wärmer, Elektrobit Automotive GmbH

This manuskript ist not available according to publishing restriction.

Thank you for your understanding.

(C) Springer Fachmedien Wiesbaden GmbH 2017

M. Bargende, H.-C. Reuss, J. Wiedemann (Hrsg.), 17. Internationales Stuttgarter Symposium,

Proceedings, DOI 10.1007/978-3-658-16988-6_105 